\title{
Gratitude in long term care
}

\begin{abstract}
An exploratory study was conducted to examine the effectiveness of a group gratitude intervention with 29 permanent residents at a long term care/skilled nursing facility in improving elder mood, behavior and well- being over a 3 week time period. The sample included individuals diagnosed with dementia, other cognitive impairment, major depressive disorder, insomnia and generalized anxiety disorder. The gratitude intervention consisted of asking elders to share what they are thankful for at the dinner table each day. Measures included the Elder Well Being Scale and The Dinner Rating Scale. On both measures, higher scores indicated better functioning. To test the hypothesis that post treatment elder well-being will be significantly higher than pretreatment elder well-being ratings, a oneway ANOVA was conducted. Post-hoc tests revealed a statistically significant increase in Elder Well Being Scale scores. An ANOVA of comparing Dinner Ratings demonstrated a nonsignificant increase over the 3 week experiment. Implications are discussed.
\end{abstract}

Volume 2 Issue 4 - 2015

\author{
Brooke Abrams Sunding \\ Spalding University, USA
}

Correspondence: Brooke Abrams Sunding, Spalding University, 2222 Ashley River Rd Apt 2G Charleston, SC 294I4, USA, Tel 843-300-570I,Email c2me05@hotmail.com

Received: December 10, 20I4 | Published: April II, 2015
Abbreviations: ANOVA, analysis of variance; MMSE, minimental state exam; AD, alzheimer's disease; MSS, multi-sensory stimulation

\section{Introduction}

\section{Growing geriatric population}

In the United States and worldwide the geriatric population is becoming the fastest growing age group of the human population. In the United States, factors that contribute to this trend include currently declining birth rates and an average twenty year increase in the American life span. ${ }^{1}$ This is coupled with the "Baby Boomers," the segment of the population born during the twenty years following World War II, reaching late adulthood. Female older adults outnumber male older adults by at a ratio of 132 women for every 100 men. However, from 1990 through 2007, death rates in men aged 65-84 have shown a dramatic reduction of $41.6 \% .^{2}$ There are more females with dementia than males due to the greater percentage of women in the population, but women are not more likely to develop dementia than men ${ }^{2}$. The United States Census Bureau projects that the population of people age $65+$ will have doubled by the year 2030, reaching 71.5 million Americans. By 2020 it is projected that Americans aged sixtyfive and older will make up $16 \%$ of the U.S. population. ${ }^{3}$ Worldwide projections forecast that up to twenty percent of the world's population will be $80+$ years of age by $2050 .{ }^{4}$ The oldest of the old in the U. S. population are expected to jump to twenty four percent of the population by 2050 , up from the current fifteen percent. ${ }^{5}$

\section{Growing need for services}

There is a growing need for services for older adults in the United States. The $65+$ population is more likely to encounter chronic disease, illness, or disability that leads to an increased need for health services and increases demands on the health care system. A recent epidemiologic study found that $80 \%$ of Americans age $65+$ have at least one chronic illness and that $60-65 \%$ has two or more. ${ }^{6}$ Many of these illnesses are associated with cognitive decline, such as arteriosclerosis and other cardiovascular diseases which lead to an increased likelihood of stroke $\mathrm{e}^{7,8}$ and dementia.

Obesity and diabetes also increase the risk of developing dementia. ${ }^{9-11}$ Presently, $35.7 \%$ of U.S. adults are obese..$^{12}$ Cognitive impairments such as Alzheimer's disease and other forms of dementia are associated with an increased likelihood of mood and anxiety disorders. Currently, is it estimated that dementia strikes thirteen percent, or one out of eight adult Americans age 65+ and forty-seven percent of adult Americans age 85 and older. ${ }^{13}$ Presently, sixtyseven percent of nursing home residents in the United States carry a diagnosis of some form of dementia. ${ }^{14}$ Assuming the rates of dementia among the population remain stable, without factoring in any upsurges due to increased rates of obesity or diabetes among Americans, it is estimated that in the next decade, there will be an additional 1.5 million U.S. residents aged $65+$ diagnosed with dementia. ${ }^{15}$ Thus, the growing geriatric population places increased demands on our medical and mental health care systems.

As the leading causes of death have transitioned from acute illness to chronic and degenerative diseases, there is also a greater demand for skilled nursing and assisted living facilities. ${ }^{1}$ Currently in the United States, approximately 1.5 million older adults reside in nursing homes and forty five percent are $85+$ years of age. ${ }^{14}$ Thus, there is a high need for effective and efficient interventions aimed at increasing quality of life for the growing population of elderly persons living in long term care facilities.

Older adults living in long term care facilities frequently face challenges of emotional and behavioral problems associated with dementia. These may include depression, irritability, social isolation, lack of interest in physical activity, confusion, aggression, a motivation fearfulness and inability to follow directions. ${ }^{16}$ A study of a community dwelling sample of older adults with and without dementia found that individuals with dementia were significantly more likely to suffer from depression, anxiety, apathy and agitation than participants without dementia. ${ }^{17}$ In a two year longitudinal study, McCarthy et al., ${ }^{18}$ tracked caregiver reports of behavioral problems and Mini-Mental State Exam (MMSE) scores in 150 participants diagnosed with Alzheimer's Disease.

Results indicated an increase in cognitive problems such as recognizing familiar people and objects, increase in apathy, increase in emotional problems and an increase in impulsive behaviors as the disease progressed. Neuroimaging has shown that the brains of individuals with depression and dementia show increased activation of the amygdala which may be expressed as negative affect and rumination. Individuals with decreased cognitive functioning need interventions that can regulate the over-activated limbic system. Approaches in positive psychology, such as exercises in gratitude 
have been shown to be helpful in improving mood in younger populations and may lead to improved mental health among older adult populations as well. This study aims to explore the effectiveness of a gratitude intervention with elders with dementia in improving elder mood, behavior and well- being. The gratitude intervention, i.e., asking elders to share what they are thankful for at the dinner table each day, is not overly demanding of elder's cognitive functioning yet it may help decrease negative emotion and stress. It is also hoped that elders might use the regular practice of gratitude as a coping mechanism for future stressors. It is hoped as well that the gratitude intervention would be effective with older adults as it falls in line with the final developmental task of older adults, age 60 and older, as defined by Erik Erikson ${ }^{19}$ "ego integrity versus despair" in later adulthood as it is has similarities to reminiscence or life review.

\section{Literature review}

\section{Brief introduction to study}

During the last decade, positive psychologists have widely researched human strengths such as resiliency, positive emotions such as happiness and concepts such as life satisfaction. ${ }^{20-22}$ This positive psychology movement, organized and spearheaded by Martin Seligman, $\mathrm{PhD}$ emphasizes positive aspects of human functioning and resiliency instead of strictly focusing on dysfunction and pathology in order to obtain a more complete understanding of human experience..$^{23}$ Recently, researchers of positive psychology have begun studying gratitude ${ }^{24-26}$ However, participants in most gratitude research to date have been college students and younger adults. ${ }^{27,28}$ Currently, there is a dearth of research examining gratitude in older adults. There is also a lack of research examining gratitude induction as a group intervention. The aim of the present study is to examine the effectiveness of a group gratitude intervention in improving aspects of elder well-being and the elder peer interactions at an assisted living facility.

\section{Overview of positive psychology}

Positive psychology differs from traditional psychology's adherence to the medical model in several ways. First positive psychology places more emphasis on the context or social environment of the individual. ${ }^{29}$ Like systems theory, positive psychology is interested in viewing the identified client in terms of his or her interpersonal relationships, but extends this to include the relationship of the individual within the community and within larger institutions. This includes interpersonal skills, work ethic, altruism and being a responsible member of society. Positive psychology also considers the role of the environment and the resources available to the individual at that time.

Secondly, positive psychology diverges from traditional psychology by focusing on the study of human strengths. Historically psychology has focused on abnormality and dysfunction. Positive psychology expands this viewpoint to include the study of healthy individuals, systems and communities. ${ }^{30}$ This is similar to Bronfenbrenner's ${ }^{31}$ ecological systems theory which identifies five environmental systems with which individuals interact ranging from the microsystem (e.g., peers, family, religious group, school) to the chronosystem (e.g., current political policies and current societal expectations). Positive psychology examines optimal human functioning, wellness and traits that lead to successful living and life satisfaction. This includes the study, happiness and factors related to these phenomena such as gratitude, spirituality and optimism. Positive psychology does not deny the necessity of identifying and treating psychopathology or criticize efforts to understand mental health problems. It simply calls practitioners to move beyond these efforts and broaden horizons to include the study of healthy human functioning in order to reach an understanding of the full range of human experience. "Positive psychology revisits 'the average person,' with an interest in finding out what works, what is right and what is improving". ${ }^{32}$

Also, positive psychology differs from traditional psychology in its view of pathology. ${ }^{33}$ In traditional psychology, there is still a tendency to categorize functioning into discrete, dichotomous categories of normal versus abnormal. Positive psychology views human functioning as falling along a continuum of normality. Positive psychology focuses on "understanding the entire breath of human experience, from loss, suffering, illness and distress through connection, fulfillment, health and well-being". ${ }^{34}$

Finally, positive psychology calls for a revision of treatment goals. Positive psychology holds that the mental health field should strive beyond treatment goals of simply a reduction of symptoms or a return to previous functioning to reach goals to increasing the individual's "capacity to thrive and flourish" 35 and a greater appreciation of human potential. ${ }^{34}$

\section{Geriatric well being}

More research is needed on interventions to improve overall well being and quality of life in older adults as this population segment is rapidly increasing. ${ }^{36}$ The behavioral health field will need to expand and develop specialized services to meet this growing demand.

The time period of later life for an individual is sometimes described as the "golden years" and conjures forth images of wisdom and peaceful reflection on a life well lived. Indeed researchers have examined the relationship between sense of well-being and age. Charles et al., ${ }^{37}$ conducted a longitudinal study measuring both positive and negative affect over a time period of twenty-three years. Participants were between fifteen and ninety years of age at the beginning time point of the study. The diversity of ages in this sample, followed over time, allowed researchers to look for possible cohort effects on affect. Results indicated that frequency of negative affect decreased over time, across all age groups. Frequency of positive affect was found to be relatively stable across the life span for all age groups. No cohort effects were found for measures of affect.

Researchers Carstensen et al., ${ }^{38}$ assessed the frequency and intensity of emotional experience among 184 adults aged 18 to 94 , searching for differences related to age. Participants were asked to self-report their current emotional experience whenever they were signaled by an electronic pager as they went about their daily lives. Participants were randomly paged five times a day for one week. Results indicated no age differences in the frequency of experiencing positive emotions. However, results indicated a decrease in the frequency of negative emotions related to increased age until age 60, at which a slight increasing trend appeared. No significant differences in the experience of the intensity of emotion were found to be related to age.

Myers \& Diener ${ }^{39}$ performed a literature review of studies examining factors relating to happiness and found no association with an individual's age and subjective well-being. Also, no evidence was found to suggest a link between gender, race or presence of a disability and subjectively rated happiness. Financial resources were also unrelated to subjective well being provided that basic daily living necessities were afforded. However, evidence was found that suggests an individual's health and social support, including marital, work and family relationships are increasingly related to subjective well-being as the individual advances in years. Myers \& Diener $^{39}$ concluded that, 
"Satisfaction is less a matter of getting what you want than wanting what you have" (p.13). Furthermore, evidence suggested that the happiest people scored higher on measures of self-esteem, sense of personal control, optimism and extraversion than less happy people. Moreover, happier people engaged more frequently in meaningful activity and were more religiously active than less happy people.

Diener \& $\operatorname{Suh}^{40}$ found similar results in their review of four international surveys of quality of life and well-being among older adults. Diener \& $\mathrm{Suh}^{40}$ found evidence to suggest that although factors typically associated with well-being including income, physical health and a sense of personal control tended to decrease over the life span, along with a decline in protective factors such marriage due to a higher rate of widowhood, no significant decline in self-reports of subjective well-being was found to be associated with age. The authors suggest this indicates a successful adaption to changes in resources related to age, meaning that despite the lack of protective factors, older adults were responding to life's challenges with greater adaptation.

However, Wilson \& Ross ${ }^{41}$ conducted a study of college students and their parents and found that both participants rated their current selves more favorably than their past selves at younger age. The authors proposed that self-reports of well-being may be positively skewed due to a self-serving bias. They propose that as individual's age, they may unconsciously report being happier than they really are due to a desire to feel good about their present selves and current circumstances. Other longitudinal studies have found that an individual's sense of well-being remains relatively stable over the life span. ${ }^{42,43}$

Increased age is associated with an increased likelihood of physical complaints. ${ }^{44}$ The link between physical health and mental health is well established; ${ }^{45-47}$ thus older adults are more likely to need interventions aimed at improving overall quality of life.

\section{Depression and dementia}

Strides have been made in the treatment of mental health disorders associated with aging. Unfortunately, depression in older adults is often overlooked, masked by physical complaints, or it is simply attributed to being a natural part of aging and left untreated. ${ }^{48,49}$ Complaints of chronic pain of uncertain origin have been found to be significantly related to previously undiagnosed symptoms of depression in older adults. ${ }^{50}$ Further contributing to the under diagnoses of depression in older adults is that depression in older adults has a tendency to develop more gradually, even over the course of years, compared to a quicker onset of depression in younger adults. ${ }^{51}$ Also, older adults are more likely to manifest physical symptoms of depression such as sleep difficulty, changes in appetite and fatigue versus more explicit tearfulness and depressed mood which may cause symptoms to be misattributed to a medical condition. ${ }^{51}$ Physical disability has been found to be a significant risk factor for developing late-life depression. ${ }^{52}$ For individuals with dementia, depression can increase rate of cognitive decline. ${ }^{53}$

Dementia is characterized by a progressive deterioration in cognitive functioning. Dementia includes impairment in memory, orientation and use of language, problem solving and information processing. With such focus on the cognitive aspects of dementia, it is important not to lose sight of the emotional, behavioral and physical challenges associated with it as well. Emotionally, the individual living with dementia may experience mood swings, irritability, anxiety and confusion. ${ }^{54}$ In the early stages of dementia, individuals are aware of having cognitive difficulties and this is experienced as very stressful, frustrating and frightening. ${ }^{54}$
A qualitative study examining interviews of twenty men whom were recently diagnosed with Alzheimer's disease found an overall theme of a struggle for the individuals to balance their desire to maintain their previous sense of self with a need to incorporate this new information and construct a new sense of self..$^{55}$

Qualitative studies have attempted to identify stages of the emotional experience of individuals receiving a diagnosis of dementia. Although these models are not in perfect alignment, there is much overlap which suggests that a comprehensive model of the range of emotional reaction to the diagnosis of dementia will be identified. These studies and a summary of their identified stages follow. Cohen et al., ${ }^{56}$ identified the stages of Recognition and Concern, Denial, Anger, Guilt, \& Sadness, Coping Maturation and Separation from Self. Similarly, Keady \& Nolan $^{57}$ categorize the stages of Slipping/Suspecting, Covering Up/Revealing, Confirming, Surviving/Maximizing and Disorganization/Decline/Death. Pratt \& Wilkinson ${ }^{58}$ classified the stages as Noticing symptoms, Diagnosis process/disclosure, Crisis, Prognosis, Denial, Maximizing and Distress. Lastly, Aminadeh et al., ${ }^{54}$ identified the following stages, not noticing symptoms, Noticing and covering up/ Noticing and revealing, Diagnosis process and disclosure, Confirming or shock, Denial/ Crisis/ Maximizing, followed by Disorganization/ Adaption.

A typical pattern of memory decline with dementia is initial difficulty learning and remembering new information, primarily affecting short-term memory. Implicit or automatic memory has been found to remain intact longer than explicit or effortful short term memory. ${ }^{59}$ This is followed by impairment in long-term memory and primary memory ${ }^{60}$ Cognitive decline appears to follow the reverse sequence of Piagetian development. ${ }^{61,62}$ Procedural memory is relatively robust to the effects of dementia until the later stages. ${ }^{63}$

Demonstrating the importance of a comprehensive picture of the experience of living with dementia, researchers have proposed a stress process model for individuals with dementia. ${ }^{64}$ This model identifies factors that may mediate an individual's experience living with dementia including personality, social support, financial resources, spirituality and care values such as concerns about becoming a "burden" on caregivers and distress regarding dependency. Also identified in this model are the stressors of role strain within family roles, work roles and strains within the caregiver dyad. These stressors can contribute to depression, anxiety and agitation related to dementia. This model captures the subjective stressors of dementia in addition to the objective stressors such as cognitive impairment, decline in functioning and behavioral problems.

Depression and dementia are frequently found to be co-occurring. ${ }^{65}$ Imaging research has found late-life depression to be associated with the later development of Alzheimer disease ${ }^{66} \mathrm{~A}$ five year longitudinal study of community dwelling individuals with and without dementia found that individuals with dementia reported significantly more depression, apathy and anxiety than individuals without dementia. ${ }^{67}$ Impairment in executive functioning has been found to be significantly associated with agitation, anxiety and depression. ${ }^{68}$ As some symptoms of dementia and depression overlap such as sleep problems, loss of appetite, irritability and difficulty concentrating, co morbid depression in an individual previously diagnosed with a dementia may be unintentionally overlooked.

\section{Treating depression and dementia}

A behavioral approach has been found to be useful in treating depression associated with dementia. This approach includes 
treatment providers identifying antecedents and consequences of problematic behavior, making changes in the environment such as clearly labeling objects or camouflaging exits and use of behavioral activation such as structured schedule of range of motion exercise, social activities, or craft activities. Teri et al., ${ }^{69}$ randomly assigned 153 participants diagnosed with Alzheimer's disease (AD) to a routine care group or an exercise/behavioral management group. Results indicated lower depressive symptoms at three months and twentyfour months for participants in the behavioral group compared to the routine care group. Similarly, Proctor et al., ${ }^{70}$ randomly assigned 120 participants residing in nursing homes to either a routine care group or a behavioral management group. Results indicated lower symptoms of depression in the behavioral management group compared to the routine care group.

Reminiscence therapy has also been applied to elders with dementia and depression. ${ }^{71}$ Reminiscence therapy includes a life review of past events and experiences. The benefit is believed to be in helping the individual identify strengths and find meaning in their past experiences to cope with current life stressors. Reminiscence therapy has been found to be associated with improved mood, however, the gains were found to be temporary. ${ }^{72-74}$ Use of reminiscence therapy has been associated with increased self-respect in individuals with AD. ${ }^{75,76}$ A recent meta analysis of four randomized, controlled studies found reminiscence therapy associated with mood improvement for up to four weeks, yet found inconclusive evidence to support the use of reminiscence therapy in the treatment of dementia with depression. ${ }^{77}$ A review by Jones \& Beck-Little ${ }^{78}$ found reminiscence therapy to be effective in the treatment of depression among institutionalized, elderly women, improving the women's feelings of accomplishment and future outlook. Jones and Beck-Little also suggest that reminiscence therapy may be particularly useful with rural dwelling elders who may be more uncomfortable with traditional talk therapy. In a study by Chao et al., ${ }^{79}$ group reminiscence therapy was used with nursing home residents in Taiwan and found to significantly increase elders' self-esteem; a positive trend was found in decreasing elders' depression, yet was not statistically significant.

A meta-analysis of fourteen random, controlled studies treating depression in the elderly with either cognitive behavioral therapy, reminiscence therapy, traditional psychotherapy, or antidepressants found both reminiscence therapy and cognitive behavioral therapy to be effective, more effective than placebo or treatment as usual, but did not find them to enhance antidepressant therapy. ${ }^{80}$

Another approach to the treatment of dementia with depression is reality orientation. Reality orientation entails repetitive reorientation of the individual to person, place and time and the use of orientation aids such as calendars, labeled photos and clocks. Some evidence of adverse effects such as anger, frustration and depressed mood have been noted with the use of reality orientation..$^{81}$ It is possible that this type of reorientation raises anxiety in those that are reminded of what they have forgotten. Other studies have found mixed results. For example, a Meta analysis by O'Connel et al., ${ }^{82}$ found reality orientation to not show any significant improvement in the mood or disruptive behavior of individuals with dementia. However, a Cochrane Meta analysis of six studies which employed random assignment and used reality orientation as a treatment for dementia found significant benefits in areas of cognition and behavior of individuals diagnosed with dementia. ${ }^{83}$ However, it should be noted that the review by Spector et al., ${ }^{83}$ has since been withdrawn and revised as a review of the usefulness of cognitive stimulation as a dementia intervention instead of reality orientation and additional studies were included. ${ }^{84}$ This review ${ }^{84}$ found cognitive stimulation to be an effective intervention for individuals with mild to moderate dementia.

Snoezelen therapy or Multi-Sensory Stimulation (MSS) has also been applied to the treatment of mood in individuals with dementia. ${ }^{85}$ MSS involves multi-sensory stimulation of the senses without cognitive demands. The senses are stimulated using tactile objects, lights, smell and music. The efficacy of snoezelen therapy in improving mood in individuals with dementia has been studied. Baker et al. ${ }^{86}$ randomly assigned 50 elders with moderate to severe dementia to receive either MSS or care as usual. Results indicated improved mood and behavior for the MSS group compared to the care as usual group, however, these gains were found to be temporary. In contrast, a Meta analysis of four randomized trials, found no significant effect of MSS therapy on mood for individuals with dementia. ${ }^{87}$ Another study investigated the efficacy of snoezelen therapy with 125 individuals with moderate to severe dementia residing in a long term care facility and found a significant improvement in mood, increase in social interaction and decrease in aggression and apathy compared to the care as usual group. ${ }^{88}$

Stimulated Presence Therapy has also been applied to the treatment of dementia. Camberg et al. ${ }^{89}$ randomly assigned 54 elders diagnosed with severe dementia to either a care as usual group, stimulated presence group, or a placebo group. Participants in the stimulated presence group were exposed to a cassette tape recording of someone talking about meaningful events in the elder's life. Participants in the placebo group were exposed to a cassette tape recording of someone reading the newspaper. Results indicated that participants in the stimulated presence group were rated to be less agitated and to show more frequent happy facial expression than individuals in the placebo group. However, no significant differences were found between the stimulated presence group and the care as usual group.

It has been established that laughter improves the body's immune response $\mathrm{e}^{90-92}$ and reduces perceived experience of pain. ${ }^{93,94}$ Humor therapy has also been used as an intervention to treat the behavioral and psychological symptoms of dementia. ${ }^{95}$ Brodaty et al. ${ }^{96}$ examined the effectiveness of humor therapy with nursing home residents. Their study included 400 nursing home residents from thirty-six different facilities. Participants were randomly assigned to receive twelve weeks of humor therapy or treatment as usual. The humor therapy consisted of a professional performer engaging residents in prop comedy, music and mime in nine, two-hour sessions. In addition, in the humor therapy group, a nursing staff member was assigned to encourage use of humor in the routines of daily care. Results indicated a decrease in agitated behavior in the humor therapy group compared to the control group at throughout the twelve week study and at twenty-six week follow up.

The effectiveness of Montessori-based interventions on the mood and activity level of individuals with dementia has also been investigated. ${ }^{97}$ In this study, sixteen residents in a long-term care facility with advanced dementia participated in Montessori activities in 30minute sessions, twice a week and regular unit programming activities during the rest of the week for a nine month period. Montessori-based activities included sorting objects by color, counting objects, sorting pictures based on different categories such as "happy" or "not happy" and bingo played with common phrases rather than numbers and letters. Regular unit programming activities included group exercise, watching movies, discussion of current events, playing musical instruments, storytelling, puzzles and trivia. Participants were observed and rated by staff in terms of constructive engagement, passive engagement, non-engagement, or self-engagement and affect 
during both types of activity programming. Results indicated that the participants demonstrated more constructive engagement and less passive engagement during the Montessori-based activities than the activities as usual and were also rated as displaying more pleasurable affect and less anxiety when engaged in the Montessori-based activities than the activities as usual. The authors suggest that Montessori-based activities may be especially helpful for individuals with dementia as they are less cognitively demanding, but still allow an individual to utilize their remaining abilities and provide sensory based activities. They postulate these activities are appropriate for individuals with dementia as they are commensurate with the developmental model of cognitive development and aging. This model posits that with dementia, cognitive abilities are lost in the reverse order of which they were developed during childhood. ${ }^{98,62}$ Thus, skills involving the earliest types of learning utilizing procedural and implicit memory and motor memory and rehearsal are the last to decline in individuals with dementia. Also, the physical materials involved in the Montessori activities provide a compensatory, external memory aid.

In a pilot study, Camp \& Judge ${ }^{99}$ examined the effect of an intervention in which twelve, older adults with dementia residing in a nursing home taught Montessori-based lessons to visiting preschool children, ages two to five years old. These lessons occurred once a week for thirty to forty-five minutes for seventy-five weeks. The aim of the intervention was to increase engagement and decrease apathy in the older adults as measured by caregiver observations. Results indicated a significant decrease in apathy and increase in engagement the older adults on the days they worked with the children compared to the days they did not. Vance \& Johns ${ }^{100}$ also found Montessori materials aided in cognitive performance and social behavior of adults with dementia.

\section{Factors related to mood in older adults}

Other factors have been identified to be related to mood in older adults. Butler \& Ciarrochi ${ }^{101}$ found in a study of older adults, that increased psychological acceptance was positively correlated with emotional well-being. Psychological acceptance was defined as willingness to experience thoughts, feelings, memories and sensations without attempts to avoid or change them.

The relationship between perceived control among older adults and mood has also been examined. Langer \& Rodin ${ }^{102}$ assigned ninety-one nursing home residents to two groups designed to differ in messages of empowerment communicated from residential staff. Residents in the first group were given a speech about personal responsibility and presented with the choice to adopt a plant of their choosing and informed that the care of the plant would be the responsibility of the resident, not nursing home staff. Participants in the first group were also informed that a movie would be shown later and that residents could choose when and if they wanted to view the movie.

The second group was treated in a less empowering way. They were given a speech reminding them that staff was responsible for the care of residents. The participants were then assigned a plant and informed that the staff would be responsible for the care of the plant. Next, residents in the second group were assigned a movie viewing time.

Results indicated that participants in the empowerment group showed significantly higher scores on a measure of well-being, participated more in activities and were more alert than participants in the less empowered group. At the eighteen month follow-up, these gains were maintained. ${ }^{103}$ Brown $^{104}$ also studied the relationship between care recipients' perceived sense of control and emotional well being.
In general, it was found that individuals with a higher perceived sense of control had better psychological well being. Interestingly, it was found that for individuals with severe physical limitations requiring much assistance in activities of daily living, having a lower sense of perceived control was associated with better emotional well being.

Sheldon \& Kasser $^{105}$ conducted a study in which 108 adults between the ages of seventeen and eighty-two were administered questionnaires containing measures of positive mood, negative mood and life satisfaction. A measure of psychological maturity assessed engagement in intrinsically motivated and extrinsically motivated behaviors. Participants were asked to list personal goals and these were coded for Eriksonian ${ }^{106}$ tasks of identity, intimacy, generativity and ego integrity. Results indicated that older adults had a more internal locus of control when compared to younger adults. Analysis of thematic content revealed that older adults were striving more towards tasks of generativity and ego integrity than younger adults whom were more likely to strive towards tasks of identity. All age groups were equally likely to strive towards tasks of intimacy. Overall, age was found to be positively correlated with subjective well being.

In a three part, cross-cultural study, researchers examined the relationship between subjective well-being, age and sense of autonomy. ${ }^{107}$ Part one of the study involved 170 adults, aged twenty to eighty-two. Participants completed a questionnaire assessing positive mood, negative mood, life satisfaction and feelings of autonomy or internal motivation regarding civic and interpersonal duties. These duties included behaviors such as voting and tipping for service. Results indicated that age was significantly positively correlated with sense of autonomy and autonomy mediated subjective well being.

Part two of the study involved 263 college students and their 348 parents. Participants completed questionnaires assessing feelings of autonomy regarding social obligations of the roles of 'child,' 'employee,' and 'United States citizen' and subjective well being. Results indicated age was positively associated with subjective wellbeing and that feelings of autonomy related to roles of employee and citizen significantly mediated this effect.

Part three of the study involved 213 adult residents of Singapore, a collectivist culture. Participants completed questionnaires assessing subjective well-being and perceived autonomy when performing social duties such as helping relatives and obeying parents, teachers, bosses and other authority figures. Results indicated that age was positively correlated with perceived autonomy in performance of social obligations and subjective well-being was related to this internal motivation. This suggests that internalization of social duties is important for subjective well being in both individualistic and collectivistic cultures. The authors theorize that chronological age may be linked with increasing autonomy as individuals face Erikson's psychosocial crisis of "ego integrity versus despair" in later adulthood. In this stage, initiated by a realization of mortality, individuals strive to find meaning and satisfaction in life review and retrospection. ${ }^{106}$ These results are in line with Deci \& Ryan's self-determination theory which posits that autonomy and internal motivation is a human need and necessary for psychological well-being. ${ }^{108}$

Positive psychology has introduced the concept of positive aging. Vaillat ${ }^{109}$ states that, "The mission of positive aging is very clear: to add more life to years, not just years to life". Vaillat defines positive aging to include physical health, emotional health and engagement in meaningful activity. 


\section{Defining gratitude}

Recently, the benefits of gratitude have been explored.24,26 Researchers have studied gratitude as both a temporary emotional state and as an enduring personality trait. The state of gratitude has been described as emotion resulting from the recognition that something beneficial has happened for you and that an external agent is mostly responsible for this. ${ }^{110}$ This external agent may be another person or a spiritual higher power. Gratitude as a personality trait has been described as a disposition of experiencing gratitude often and easily, enduring across time and across different settings. ${ }^{110}$

Gratitude is also a component of many religions and spiritual orientations. Watts et al., ${ }^{111}$ call for an integration of religion and psychology with regards to common concepts of hope, forgiveness and gratitude. The authors explore the concept of gratitude "as an emotion, an attitude, a moral virtue, a habit, a personality trait and a coping response" (p.283). Emmons \& Crumpler ${ }^{112}$ note that nearly every language has a word for gratitude.

A Gallup Poll conducted in 1996 surveyed a random sample of 1,003 Americans and asked participants to name what they were thankful for. ${ }^{113}$ Results indicated that family and health were the most cited reasons for gratitude. Results also indicated that older people were more likely than younger people to report health as a reason for thanks. Thus, it appears that in older adults, health condition may significantly impact their feelings of gratitude.

\section{Relationship between gratitude and mood}

A pre-sleep gratitude exercise has been found to be positively correlated with sleep quality and sleep duration, independent of personality traits. ${ }^{26}$ Smith $^{114}$ found the intervention of nondenominational prayer to be associated with feelings of gratitude and higher quality of life ratings among individuals diagnosed with dementia.

Chan ${ }^{115}$ examined the effect of an eight week gratitude intervention with 96 school teachers in Hong Kong. A comparison of pre-test and post-test subjective well-being measures indicated a statistically significant increase in subjective well-being following the gratitude intervention. Sheldon \& Lyubomirsky ${ }^{28}$ found that having individuals write out their blessings and visualize their best possible selves generated a temporary, but significant elevation in mood. In this study, undergraduates were randomly assigned to one of three conditions: (a) writing about their blessings, (b) writing about their best possible self, or (c) writing about the day's events. Results indicated that both writing about blessings and writing about their best possible self were associated an increase in positive mood. The control condition, writing about the day's events, did not result in an increase in positive mood. No statistically significant differences were found between the writing about blessings condition and the writing about best possible self condition.

In an internet-administered study by Seligman et al., ${ }^{116} 577$ adults were randomly assigned to one of six treatment groups. The first condition asked participants to write and deliver a letter of gratitude to someone they felt grateful for, but had not thanked. The second condition asked participants to write about three good things that happened each day for one week. The third condition asked participants to reflect on personal strengths. The fourth condition asked participants to complete a character inventory identifying personal strengths and attempt to use these personal strengths in new ways during the week. The fifth condition asked participants to complete a character inventory identifying personal strengths and attempt to use these personal strengths more frequently during the week. The sixth condition, the control asked participants to journal about early memories. Results indicated that participants asked to write about three good things that happened each day for one week and participants asked to use personal strengths in new ways during the week both demonstrated a significant increase in positive mood and decrease in depressive symptoms compared to pre-treatment measures at the six month follow-up. Participants asked to write and deliver a letter of gratitude also demonstrated positive changes in mood; however these gains were only maintained for one month.

Boehm et al., ${ }^{117}$ examined the effectiveness of positive activity interventions on improving life satisfaction among 220 adults of different cultural backgrounds, Anglo Americans and Asian Americans. Participants were randomly assigned to either of the two treatment conditions or the control group for six weeks. The first treatment condition was expression of optimism, where participants were asked to imagine and write about their best possible futures. The second treatment condition was expression of gratitude, where participants were asked to write letters expressing gratitude towards friends or family members. In third condition, or the control group, participants were asked to write out their activities of the past week. Results indicated improved life satisfaction among the optimism and gratitude groups for both Anglo Americans and Asian Americans when compared to the list past experiences condition. However, improvements were more noticeable among the Anglo Americans.

Lyubomirsky et al., ${ }^{118}$ examined the effectiveness of expressing optimism and expressing gratitude on well-being in a study of 355 college students. This eight month long study also looked for any effects of self-selection and any effects of sustained effort invested by the participant on well-being outcome. To examine the effects of selfselection, the experiment was advertised in two separate flyers. On one flyer it was described as a happiness intervention and on the other it was described as a cognitive intervention. Based on which study the student selected, they were sorted into "low" or "high" motivation to improve happiness groups. Regardless of which flyer students responded to, they were informed that the study was designed to improve well being.

Participants were then randomly assigned to either the optimism or gratitude treatment condition, or the control group. In the optimism condition, participants were asked to spend fifteen minutes a week visualizing and writing about their best possible future selves. Each week they were given a category of their future to write about such as romantic future, educational future, career future, physical health future, etc. In the gratitude condition, participants were asked to spend fifteen minutes a week recalling times in their life when they felt grateful for something someone did for them and to write but not send, a letter expressing gratitude towards that person. In the control group, participants were asked to spend fifteen minutes writing about the previous week's activities. Well-being was assessed at the beginning of the eight week intervention period, immediately afterward and six months afterward. Participant's writings were then read by research assistants and scored for effort, independent of length of writing or writing skills demonstrated.

Results indicated significant increases in well-being for those students in the gratitude and optimism conditions that self-selected the happiness study at the conclusion of eight week intervention and at the six month follow-up. The amount of effort invested in the gratitude and imagining best possible future selves was found to be positively correlated with treatment outcome for these students. Significant gains in well-being were not observed for students in the 
treatment conditions that did not self-select the happiness study. Also, no significant gains in well-being were found for self-selected or non self-selected students in the control condition. Overall, it was found that a desire to improve happiness was necessary, but not sufficient in itself to improve overall well-being.

Watkins et al., ${ }^{119}$ describe the reciprocal nature of the relationship between gratitude and positive mood as a "cycle of virtue." In this cycle, being in a positive mood makes one more likely to notice positive things in the environment; recall positive experiences and attribute good intentions to others. In this way, being in a positive mood increases the likelihood of experiencing a state of gratitude. It then follows that being in a state of gratitude contributes to positive emotions and the cycle continues.

\section{Further examination of gratitude}

Emmons \& McCullough ${ }^{27}$ conducted a series of three experiments examining the relationship between gratitude, mood, health and behavior. In Emmons \& McCullough's first experiment, 192 college students were randomly assigned one of three conditions: gratitude, hassles or neutral events. In the gratitude condition, participants were asked to list what they were grateful for once a week, for ten weeks. Participants in the hassles condition were asked to list daily hassles that negatively impacted them once a week, for ten weeks. Participants in the neutral condition were asked to list recent life events once a week, for ten weeks. Results indicated that participants in the gratitude condition reported significantly less physical ailments, greater satisfaction with overall life and a more optimistic future outlook than participants in the hassle listing or neutral condition.

In Emmons \& McCullough's ${ }^{27}$ second experiment, 157 college students were randomly assigned to one of three conditions: gratitude, hassles or downward social comparisons. In the gratitude condition, participants were asked to list what they were grateful for once a day, for fourteen days. Participants in the hassles condition were asked to list hassles that negatively impacted them once a day, for fourteen days. Participants in the downward social comparison condition were asked to list ways in which they were better off than others once a day, for fourteen days. Results indicated that participants in the gratitude condition reported significantly more positive mood and engaged in more pro social behaviors than participants in hassle listing or downward social comparison condition.

In Emmons \& McCullough's ${ }^{27}$ third experiment, sixty-five adults diagnosed with neuromuscular disease were randomly assigned to one of two conditions: gratitude or control. In the gratitude condition, participants were asked to list what they were grateful for once a day, for twenty-one days. In the control condition, participants simply completed the mood, health and behavior ratings once a day, for twenty-one days. Results indicated that participants in the gratitude group reported significantly more positive affect, greater optimism for the future, better sleep quality and a greater connectedness with others than participants in the control condition. In addition, observer ratings obtained from significant others of the participants also indicated greater positive affect for participants in the gratitude condition than for participants in the control condition.

Using similar procedures, Froh et al., ${ }^{24}$ randomly assigned 221 adolescents to one of three conditions: gratitude, hassles or control. Results indicated that participants in the gratitude condition reported significantly higher life satisfaction, greater positive effect and a more positive future outlook than participants in the hassles or control condition. The gains were maintained at the three week follow-up.

\section{Examining gratitude as a personality trait}

Researchers have also examined the relationship between gratitude as a personality trait and mood. A grateful disposition has been found to be associated with emotional well-being, optimism, life satisfaction and pro social behavior. ${ }^{120,121}$ Watkins et al., ${ }^{122}$ found that individuals with higher trait gratitude scores demonstrated positive memory bias, meaning that past pleasant events came more easily than past negative events to the minds those participants with higher trait gratitude scores that for participants with lower trait gratitude scores. The authors suggested that this may account for some of the relationship between gratitude and positive mood.

Chan ${ }^{115}$ examined dispositional gratitude among a sample of school teachers in China. Chan found that the teachers rated as high in dispositional gratitude were significantly less likely to report job "burnout" and reported significantly higher positive mood than teachers rated as low in dispositional gratitude.

\section{Gratitude and prosocial behavior}

A relationship has been found between expression of gratitude and prosocial behavioral response of others. ${ }^{123}$ In this study, 137 restaurant customers received their check in one of three experimental variations: with no note, with a written "thank you" on the check, or with a written "thank you" followed by the server's name on the check. Results indicated that customers in the "thank you" and the "thank you" followed by the server's name conditions left significantly higher tips than those in the no note condition. No significant differences were found between the "thank you" and the "thank you" followed by the server's name conditions.

McCullough et al., ${ }^{124}$ performed a review of gratitude literature and posited different functions of gratitude. They suggested that when an individual feels gratitude toward another individual, he/ she is motivated to engage in prosocial behavior. Likewise, the authors suggested that the expression of gratitude from the recipient of a prosocial favor positively reinforces the prosocial behavior of the gratitude recipient and encourages that individual to behave in a prosocial way again.

In a large, four part study, McCullough et al., ${ }^{110}$ investigated gratitude as a trait in college students and adults. These researchers found that individuals with trait gratitude were rated by themselves and others in their social networks as engaging in more prosocial behaviors, having a more positive mood and reporting greater life satisfaction than participants without trait gratitude. Also, even after controlling for the Big Five traits of extraversion and agreeableness and for variables of affect and social desirability, the relationship between trait gratitude and engagement in prosocial behaviors and life satisfaction remained.

\section{Gratitude and resiliency}

Gratitude as a component of resiliency has also been studied. In a qualitative study, Krause ${ }^{125}$ found gratitude towards God to be a protective factor in response to environmental stress in a study of older adults. In a longitudinal study of college students, levels of gratitude were found to be a protective factor against stress and depression. ${ }^{126}$

Krause $^{127}$ also found a similar finding in examining levels of gratitude, depression and financial strain among 818 older adults. Krause found that gratitude levels were negatively correlated with depression and gratitude seemed to protect elders from stress of financial strain. 
Also, Fredrickson, Tugade et al., ${ }^{128}$ examined the relationship between positive emotions and resiliency surrounding the terrorist attacks on the United States on September, 11th 2001. In this study, prior to the terrorist attacks, forty-six college students rated the presence of positive emotions, including gratitude and negative emotions. Two weeks after the terrorist attacks, the same participants rated their emotions again. Results indicated that the presence of positive emotions before and after the attacks were both positively correlated with resiliency and negatively correlated with the development of depression.

\section{Methods of gratitude induction}

One study examined the effect of different methods of gratitude induction. ${ }^{129}$ In this study, college students were randomly assigned to one of three gratitude conditions or the control condition. Participants in the grateful thinking condition were instructed to think for five minutes about a person they felt grateful to have had in their life. Participants in the gratitude writing condition were instructed to write for five minutes about a person they felt grateful to have had in their life. Participants in the gratitude letter writing condition were instructed to write a letter expressing thanks to a person they felt grateful to have had in their life. Participants in the control condition were instructed to write about the layout of their living room for five minutes. Results of the comparisons of pre and post-treatment affective measures indicated that all three gratitude conditions were associated with increased positive affect. The control condition showed no relationship with affect. In addition, of all three gratitude conditions, the grateful thinking condition showed the largest increase in positive effect, significantly higher than the grateful writing, grateful letter writing and control conditions.

The differences between writing, talking, or thinking about positive or negative life events on mood have been examined. ${ }^{130}$ Undergraduates were randomly assigned to one of four conditions in part one of this study. In the writing condition, students were asked to write about their worst experience fifteen minutes a day, for three days. Students in the talking condition were asked to talk into a tape recorder about their worst experience fifteen minutes a day, for three days. Students in the thinking condition were asked to think about their worst experience fifteen minutes a day, for three days. Students in the control comparison group only completed the pre and posttreatment measures. Results of the first part of the study indicated that participants in the writing and talking conditions reported more life satisfaction than participants in the thinking condition. In addition, participants in the thinking condition reported less post-treatment life satisfaction than those in the control group.

In the second part of the study, students were given the same instructions as part one, but were asked to write, talk, or think about their best life experience. Results of the second part of the study indicated that participants in the thinking condition reported greater post-treatment life satisfaction than participants in the writing and talking conditions.

In the third part of the study, students were randomly assigned to one of two conditions. Students in the thinking condition were asked to think of their happiest experience eight minutes a day for three days. Students in the writing condition were asked to write about their happiest experience eight minutes a day for three days. Within each of these two conditions, students were further divided into two conditions:

(a) continual replay or (b) systematic analyzation. In the continual replay condition, students were asked to continually replay in their minds the day of their best experience during their assigned writing or thinking exercise. In the systematic analyzation condition, students were asked to systematically analyze the best day of their experience during their assigned writing or thinking exercise. Thus for the third part of this study, there were four different conditions. Results of the third part of the study indicated that participants in the thinking with continual replay condition reported significantly greater post-treatment life satisfaction than participants in the writing with systematic analyzation condition.

\section{Why does gratitude work?}

Lyubomirsky et al., ${ }^{131}$ propose that gratitude may be linked with emotional well-being due to counteracting effects of hedonic adaptation. Hedonic adaptation refers to the theory of Brickman \& Campbell ${ }^{132}$ that individuals tend to return to a baseline of happiness overtime regardless of experiencing positive and negative life events and that individuals have a predetermined happiness set point. Lyubomirsky et al., ${ }^{131}$ point out that intentionally engaging in counting one's blessings calls attention to and leads to appreciation of positive aspects of one's life counteracting the tendency of hedonic adaption. They also posit that engaging in gratitude gives one practice in viewing things positively and in this way increasing one's ability to cope with life stressors.

In a literature review of the effectiveness of positive activity interventions such as gratitude, researchers Layous et al., ${ }^{21}$ propose a three prong model of how these treatments aid in alleviating depressive symptoms. First the authors posit that positive activity interventions increase positive mood and decrease negative mood. Next, this shift in mood is accompanied by a shift to a more positive, more flexible and less inwardly focused mindset. Third, this change in mindset and mood increases the likelihood of the individual engaging in positive activities such as connecting with others, pursuing goals and interests and practicing healthy self-care behaviors, counteracting the behavioral inhibition and anhedonia typical of depression.

Watkins ${ }^{133}$ proposes five mechanisms in which the practice of gratitude enhances subjective well-being. First, he suggests that it "intensifies well-being." Second, he suggests that it counteracts hedonistic adaption. Third, the practice of gratitude increases coping response of keeping a positive perspective. Fourth, the practice of gratitude improves the ease of retrieval of and accessibility of pleasant past memories. Fifth, the expression of gratitude may make a person more likely to have more social benefits. These social benefits refer to actual more objectively determined social life events from the Life Events Checklist that are less likely to be misre called as more positive or negative than they actually were.

\section{Goal of present study}

The goal of the present study is to examine the effects of a group gratitude dinner intervention in an assisted living facility on the emotional well being and dinner behavior of the resident elders. The hypothesis of the present study is that post treatment elder well-being will be significantly higher than pretreatment elder well-being ratings. A second hypothesis is that post treatment dinner atmosphere ratings will be significantly higher than pretreatment dinner atmosphere ratings.

\section{Methods}

\section{Participants}

The sample for this study was composed of twenty-nine permanent residents at a long term care/ skilled nursing facility. The mean age of 
participants was 87.7 years old. The ages ranged from sixty-five to ninety-nine years old. All participants were Caucasian. These data are shown in Table 1.

Table I Demographic Information

\begin{tabular}{ll}
\hline \multicolumn{2}{l}{ Demographic Information } \\
\hline Total Participants & 29 \\
\hline Female & 23 \\
\hline Male & 6 \\
\hline Caucasian & 29 \\
\hline Mean Age & 87.7 \\
\hline Age Range & $65-99$ \\
\hline
\end{tabular}

Participants included individuals diagnosed with dementia, other cognitive impairment, major depressive disorder, insomnia and generalized anxiety disorder. Prior to beginning of study, informed consent was obtained from all elders. In cases in which the elder had appointed someone power of attorney, informed consent was obtained from these agents and assent was obtained from the elder The informed consent explained any foreseeable risks, benefits and the option to opt out.

\section{Setting}

The study was conducted at a long term care/skilled nursing facility. This facility utilizes the small-house nursing home model which was developed as part of The Green House Program. Following the smallhouse model, the maximum number of elders to reside in one house is ten. ${ }^{134}$ Each elder has a private bedroom and bathroom and spousal residents may share rooms. Elders are encouraged to decorate their rooms with personal belongings, art work, family photographs, hobby supplies and familiar furniture from home, provided they do not create fall or other safety hazards. This personalization aids in preserving the elder's individuality and personal history. ${ }^{135,136}$ In contrast to a more traditional nursing home setting with long, winding corridors, the small-house model promotes a family-like atmosphere by having an open floor layout with opportunities to socialize in the communal kitchen, dining area, hearth, living room area and garden. The living room features a fireplace hearth and ample upholstered furniture arranged in a layout that promotes conversation. Elders share meals together at one large dining table and are encouraged to help with meal preparations if they choose. Food is placed on the table in bowls and casserole dishes for serving "family style". Elders whom are able serve themselves and pass dishes around the table, promoting a family atmosphere and autonomy. Staff provides assistance when needed. Elders are invited to exercise together in the mornings and they can enjoy the weather sitting on benches in the enclosed, outdoor courtyard or help with gardening in the raised flowerbeds. Elders can participate in both organized and informal activities (e.g., playing card games) in the open living areas. All frontline staff cooks meals, clean and provide elder personal care. A three year, longitudinal study compared a facility using the small-house model and two conventional nursing facilities. ${ }^{137}$ This study found that elders in the small-house facility reported significantly higher overall quality of life and emotional wellbeing than elders in the two conventional homes.

\section{Group gratitude intervention}

For the group gratitude intervention, a staff member gathered elders just before the midday meal and encouraged each elder to share something he or she was thankful for or something good that happened that day. If an elder instead shared something negative that had happened, the staff member validated the elder's experience, "I'm sorry to hear that," and gently redirected, "Can you share something you are thankful for?" If an elder said he or she could not think of anything good that had happened or did not feel like sharing, the elder was not pressured to participate and the next elder was asked to share. The experimenter trained the staff in the gratitude intervention. The experimenter observed each Villa's first gratitude intervention to check for procedure adherence by staff. Also, to monitor treatment fidelity, the experimenter observed the gratitude intervention in each villa on an unannounced day.

This group gratitude intervention was planned for many reasons. First, it was hoped that elders with less ability to verbalize gratitude would still benefit from listening to others. Also, this intervention is simple, inexpensive and time efficient. In addition, it is an intervention that could seemingly be led by any staff member or regular visitor. This intervention is also well suited to the population as it emphasizes procedural memory, emotionally salient memory and long-term memory which are more easily accessed by individuals with dementia. The small-house model creates a family atmosphere. However, just like siblings in a family, the elders may argue and quarrel with one another during dinner. Dinners may be marked with irritability or silence. It was hoped that in addition to improving elder well being, the gratitude intervention would also improve the overall dinner atmosphere. An added benefit of an improved dinner atmosphere is that it may encourage eating and help counteract weight loss frequently associated with dementia.

\section{Measures}

\section{Elder well being scale}

During second shift, staff rated participants on the Elder Well Being Scale, a measure created for this study. Higher scores indicate better biopsychosocial functioning. This measure includes ratings of elder mood, participation in activities, sleep, cognitive functioning, social interest, activity level and general health. An overall Elder Well Being Scale score is calculated by the sum of each of the nine subscales, coded in the positive direction. See Appendix A for a copy of the Elder Well Being Scale.

\section{Dinner rating scale}

Staff observations of elders during the midday meal were rated on a measure created for this study. This measure marked the presence or absence of negative comments, encouraging statements, arguments, physical aggression and verbal aggression during the dinner hour. A global rating of the overall atmosphere of the dinner was rated on a 5-point Likert scale, with higher scores indicating a more pleasant atmosphere. The scale ranged from a rating of 1 (very unpleasant) to 5 (very pleasant). This measure tracks dinner attendance and number of elders that engaged in conversation during the meal. See Appendix B for a copy of the Dinner Rating Scale.

\section{Procedures}

This study was conducted for three weeks at each Villa. Table 2 summarizes the procedure.

\section{Week I}

For seven days, staff completed Elder Well Being ratings for each elder, each day. Also, staff completed the Dinner Rating Scale for the midday meals. Dinner proceeded as usual with no intervention.

\section{Week 2}

For seven days, ten minutes before the midday meal, staff gathered elders together in the living area. Then a staff member encouraged 
each elder to share something he or she was thankful for or something good that had happened that day. Staff completed Elder Well Being Scales and Dinner Rating Scales each day.

Table 2 Summary of procedure

\begin{tabular}{lll}
\hline Week & Dinner Intervention & Measures \\
\hline 1 & None & $\begin{array}{l}\text { ElderWell Being Scale, Dinner } \\
\text { Rating Scale }\end{array}$ \\
\hline 2 & Gratitude Intervention & $\begin{array}{l}\text { Elder Well Being Scale, Dinner } \\
\text { Rating Scale }\end{array}$ \\
\hline 3 & None & $\begin{array}{l}\text { Elder Well Being Scale, } \\
\text { Dinner Rating Scale }\end{array}$ \\
\hline
\end{tabular}

\section{Week 3}

For seven days, staff will completed Elder Well Being ratings for each elder, each day. Also, staff completed the Dinner Rating Scale for the midday meals. Dinner proceeded as usual with no intervention.

The hypothesis of this study is that elder well being scale scores and dinner rating scale scores will be significantly different from one another across the three time points of the experiment. Specifically, Week 2 Gratitude Intervention scores will be significantly higher than Week 1 Pre-Gratitude Intervention scores on both measures. Also, it is hypothesized that Week 3 Post-Gratitude Intervention scores would be significantly lower than Week 2 Gratitude Intervention scores on both measures, after the gratitude intervention was removed.

\section{Results}

\section{Elder well being scale}

A one-way within subjects or repeated-measures analysis of variance (ANOVA) was conducted to compare the effect of time (Week 1 Pre-Gratitude Intervention vs. Week 2 Gratitude Intervention Vs. Week 3 Post-Gratitude Intervention) on the mean overall Elder Well Being Scale score for each participant. An alpha level of .05 was used for all statistical analyses. These results are shown in Table 3 along with the means for each subscale.

Note: Insignificant post-hoc values omitted from table

Table 3 ANOVA Results Including Subscales by Week

\begin{tabular}{lllllll}
\hline Subscale & Mean & & & & $\begin{array}{l}\text { P } \\
\text { value }\end{array}$ & \\
& Week & Week & Week & Overall & & \\
\hline & I & $\mathbf{2}$ & $\mathbf{3}$ & & $\begin{array}{l}\text { I v. 2 } \\
\mathbf{2 ~ v . 3}\end{array}$ & I v. 3 \\
\hline $\begin{array}{l}\text { Sad/Happy } \\
\text { Hopeless/ }\end{array}$ & 3.46 & 3.53 & 3.65 & 0.103 & & \\
$\begin{array}{l}\text { Hopeful } \\
\text { Irritable/ }\end{array}$ & 3.4 I & 3.53 & 3.68 & 0.016 & & 0.003 \\
$\begin{array}{l}\text { Cheerful } \\
\text { Disinterested/ }\end{array}$ & 3.34 & 3.4 & 3.91 & 0.072 & & \\
$\begin{array}{l}\text { Enthusiastic } \\
\text { Insomnia/ }\end{array}$ & 3.13 & 3.35 & 3.65 & $<.001$ & 0.009 & $<.001$ \\
$\begin{array}{l}\text { Restful Sleep } \\
\text { Disoriented/ }\end{array}$ & 3.39 & 3.51 & 3.49 & 0.385 & & \\
$\begin{array}{l}\text { Oriented } \\
\text { Social }\end{array}$ & 3.29 & 3.27 & 3.49 & 0.182 & & \\
$\begin{array}{l}\text { Engagement } \\
\text { Low/High }\end{array}$ & 3.25 & 3.49 & 3.75 & $<.001$ & 0.024 & $<.001$ \\
$\begin{array}{l}\text { Physical } \\
\text { Activity }\end{array}$ & 3.25 & 3.44 & 3.66 & 0.002 & & 0.003 \\
$\begin{array}{l}\text { Worse/Better } \\
\text { Health } \\
\text { Overall }\end{array}$ & 3.21 & 3.19 & 3.22 & 0.925 & & \\
\hline
\end{tabular}

The analysis revealed an overall significant difference between means at the different time points $(F(2,56)=9.09, p<.001)$. Post-hoc tests using the Bonferroni correction revealed an increase in overall Elder Well Being Scale scores in the hypothesized direction during the Gratitude Intervention of Week 2 compared to Pre-Gratitude Intervention scores of Week $1(3.41 \pm 0.51$ points vs. $3.31 \pm 0.60$ points, respectively) although it was not statistically significant ( $p=$ .660). However, Post-Gratitude Intervention Elder Well Being Scale scores of Week 3 increased further $(3.61 \pm 0.43$ points). This increase in Elder Well Being Scale scores was shown to be a statistically significant increase from both Week 1 Pre-Gratitude Intervention $(p<$ $.001)$ and Week 2 Gratitude Intervention $(p=.011)$ Elder Well Being Scale scores. These results suggest that the Gratitude Intervention increased Elder Well Being Scale scores, but that this increase was not statistically significant until Week 3 , one week after the Gratitude Intervention was removed. The modest increase in Elder Well Being Scale scores in Week 2, followed by a more substantial increase in Week 3 suggests a more delayed effect of the gratitude intervention that what was originally hypothesized.

Next, a one-way within subjects ANOVA was conducted of each of the nine subscales of the Elder Well Being Scale. Some items were not found to demonstrate a significant change over time. The ANOVA result for the item measuring mood from sadness to happiness did not reveal an overall significant difference between means at the different time points $(F(2,56)=2.37, p=.103)$. In the same way, an ANOVA examining the item measuring mood from irritability to cheerfulness was not found to be significant $(F(1.2,33.7)=3.28, p=$ .072 ). Likewise, the ANOVA examining the item assessing sleep did not indicate a significant difference between the means across the time points $(F(2,56)=0.97, p=.385)$. Similarly, the ANOVA comparing the item measuring alertness did not show a significant difference across means $(F(2,56)=1.76, p=.182)$. Finally, the ANOVA examining the item measuring changes in physical health was not found to be significant $(F(2,56)=0.07, p=.925)$.

Some subscales were found to change significantly over time. The ANOVA result for the item measuring mood from hopelessness to hopefulness revealed an overall significant difference between means at the different time points $(F(2,56)=4.48, p=.016)$. Post-hoc tests using the Bonferroni correction were conducted. Although Week 2 hopefulness scores did increase from Week $1(p=.615)$ and Week 3 hopefulness scores did increase from Week $2(p=.472)$, these changes were not statistically significant. However, the increase in hopefulness scores when comparing Pre-Gratitude Intervention scores of Week 1 with Post-Gratitude Intervention hopefulness scores of Week 3 (3.41 \pm 0.65 points vs. $3.68 \pm 0.55$ points, respectively) was statistically significant $(p=.003)$.

Also, ANOVA results for the item indicating level of engagement in activities offered by the facility revealed an overall significant difference between means at the different time $\operatorname{points}(F(2,56)=$ 13.29, $p<.001)$. Post-hoc tests using the Bonferroni correction revealed an increase in level of engagement during the Gratitude Intervention of Week 2 compared to Pre-Gratitude Intervention scores of Week $1(3.35 \pm 0.55$ points vs. $3.13 \pm 0.75$ points, respectively $)$ which was not statistically significant $(p=.211)$. However, PostGratitude Intervention level of engagement scores of Week 3 increased ( $3.65 \pm 0.56$ points). This increase in level of engagement scores was shown to be a statistically significant increase from both Week 1 PreGratitude Intervention $(p<.001)$ and Week 2 Gratitude Intervention $(p=.009)$ scores.

In addition, an ANOVA examining the item measuring social engagement revealed an overall significant difference between means 
at the different time points $(F(1.66,46.56)=9.43, p=.001)$. Following the same pattern, Post-hoc tests using the Bonferroni correction revealed an increase in social engagement during the Gratitude Intervention of Week 2 compared to Pre-Gratitude Intervention scores of Week 1 ( $3.49 \pm 0.64$ points vs. $3.25 \pm 0.77$ points, respectively) which was not statistically significant $(p=.278)$. However, PostGratitude Intervention social engagement scores of Week 3 increased ( $3.75 \pm 0.48$ points). This increase in social engagement was shown to be a statistically significant increase from both Week 1 Pre-Gratitude Intervention $(p<.001)$ and Week 2 Gratitude Intervention $(p=.024)$ social engagement scores.

Likewise, an ANOVA examining the item measuring engagement in physical activity revealed an overall significant difference between means at the different time points $(F(2,56)=7.28, p=.002)$. Post-hoc tests using the Bonferroni correction revealed an increase in physical activity during the Gratitude Intervention of Week 2 compared to PreGratitude Intervention scores of Week 1 (3.43 \pm 0.67 points vs. 3.25 \pm 0.77 points, respectively)which was not statistically significant $(\mathrm{p}=$ .361 ). However, Post-Gratitude Intervention physical activity scores of Week 3 increased (3.66 \pm 0.57 points). This increase in physical activity was shown to be a statistically significant increase from both Week 1 Pre-Gratitude Intervention $(\mathrm{p}=.003)$ and Week 2 Gratitude Intervention $(\mathrm{p}=.065)$ physical activity scores.

\section{Dinner rating scale}

A one-way repeated-measures analysis of variance (ANOVA) was conducted to compare the effect of time (Week 1 Pre-Gratitude Intervention vs. Week 2 Gratitude Intervention vs. Week 3 PostGratitude Intervention) on the Dinner Atmosphere Ratings. An alpha level of .05 was used for all statistical analyses. When all Dinner Atmosphere Ratings were analyzed as a whole, no significant difference was found between the different time points $(F(2,59)=$ $1.73, p=.186)$. This result did not support the original hypothesis that Dinner Atmosphere Ratings for Week 2 would be significantly higher than Week 1 Pre-Gratitude Intervention scores and that Week 3 Post-Gratitude Intervention scores would be significantly lower than Week 2 Gratitude Intervention scores, as gratitude intervention was removed. However, the results do indicate a steady increase in overall Dinner Atmosphere Ratings over the course of the 3 week experiment.

To examine the data further, an ANOVA was conducted splitting the data by level of care. No significant differences in Dinner Atmosphere ratings were found between time points for participants in long term care $(F(2,17)=1.27, p=.318)$ or those in skilled nursing $(F(2,39)$ $=2.90, p=.067)$.

An additional ANOVA was conducted splitting the data by Villa. No significant differences in Dinner Atmosphere ratings were found between time points for participants in Villa $1(F(2,17)=1.27, p=$ $.318)$, Villa $2(F(2,18)=0.84, p=.448)$, nor the third living area, Villa $4(F(2,18)=2.78, p=.089)$. Analyses were not performed with regards to demographic data such as gender or ethnicity due to the small and nearly homogeneous sample, with the majority of participants being Caucasian females.

\section{Discussion}

Although support was not found for all the original hypotheses of this study, these results do show support for the utility of gratitude expression as a group intervention with older adults in a long term care setting. Overall Elder Well Being Scale scores were found to be significantly higher at Week 3 Post Gratitude Intervention, compared with Week 1 Pre Gratitude Intervention and Week 2 Gratitude
Intervention scores. This suggests that the gratitude intervention improved elder well-being when it was introduced and that these benefits continued to build into the following week when it was removed.

Post hoc analysis revealed that the items indicating the elders' hopefulness, engagement in activities offered by the facility, social engagement with other elders and engagement in physical activity were most improved during the three week experiment. All of these factors showed the similar trend of an increase during the week of the gratitude intervention followed by a statistically significant increase during week three when the gratitude intervention was removed. Although not at a statistically significant level, items indicating the elders' happiness and level of irritability followed a similar pattern demonstrating improvement over time.

In contrast, items indicating elders' quality of sleep, alertness and physical health did not show statistically significant improvement and displayed dissimilar patterns than the above mentioned factors. Considering the factors of the Overall Elder Well Being Scale that were significantly improved by the gratitude intervention, it may be that the gratitude intervention served as mechanism of positive cognitive reframing and as a behavioral activator. By staff providing a structured prompt, inviting each elder to share what they are thankful for at the dinner table, elders shift attention to positive events of the past and present. In shifting attention to these positive events rather than any events that might have been a source of negative rumination, the elders seemed to have improved their outlook for the future as represented by the significant increase in scores of hopefulness.

The results indicated a significant improvement in elder engagement in activities offered by the facility, social engagement with other elders and physical activity. The gratitude intervention may have encouraged these behavioral changes by improving social bonds between elders. As the elders verbally expressed their gratitude, they not only shifted their attention to positive events, but also got to know their fellow elders better by listening to their expressions of gratitude.

Witnessing someone's expression of gratitude allows the observer to learn more about the individual's personal values, interests and life experiences. Also, some expressions of gratitude express thankfulness for other elders or staff members further enhancing social bonds. An elder that feels more socially connected to fellow residents is more likely participate in residential activities. Regarding the significant increase in physical activity, it may be that gratitude induced positive outlook and improved social connections encouraged elders to participate in group exercise classes and/or walking or wheeling to visit with another elder resulting in the significant improvement in physical activity. Future research may find it fruitful to examine social bonds among elders as a treatment outcome. Similarly, it may be a good idea to examine the impact of the gratitude intervention on staff members. It may be that fostering an environment of gratitude aids staff member well-being as well.

Dinner Rating Scale results demonstrated a steady improvement in the dinner atmosphere over time. Although not statistically significant, these results paired with the significant improvements on the Elder Well Being Scale scores continue to show support for the utility of gratitude as an intervention with older adults in long term care. Considering the dementia, it is possible that a longer lasting intervention, with repetition, at more meals or more times per day, would lead to greater increases across both measures of elder wellbeing and dinner atmosphere ratings due to better memory retention.

This study was limited by small sample size. Future studies may benefit from including more participants across multiple residential 
settings. Another limitation of this study was the relative homogeneity of the participants preventing examination of the effect of demographic data such as ethnicity or gender on the treatment outcome and to some extent, limiting generalizability. Kashdan et al., ${ }^{138}$ found evidence to suggest that the expression of gratitude is more difficult for men, as it may be associated with feelings of indebtedness and vulnerability and those males may benefit less from gratitude interventions than females. A study comparing the emotional expression of German and American men, found American males to be more likely to conceal rather than express feelings of gratitude. ${ }^{139}$ Therefore, a gratitude study including a greater percentage of male participants is advisable.

In addition, this study could have been improved by more precisely tracking elder participation in activities offered by the facility. For example, keeping attendance logs of participation in art group or exercise group throughout the course of the experiment may provide a more objective measure of elder engagement in facility activities.

Another idea for improvement of this study would be to have taken staff ratings of elder well-being and dinner atmosphere twice a month in the six months prior to the experiment to have a baseline rate of fluctuation for better comparison.

Considering that overall elder well-being ratings were the highest at Week 3, after the gratitude intervention was removed. It would be informative to gather additional ratings at Week 4 , Week 5 , etc. to determine how long the beneficial effects were sustained. Likewise, it may be fruitful to study the effects of implementing the gratitude intervention for an entire month rather than one week to see if gains were any greater.

Considering the continued improvement in overall elder wellbeing even after the gratitude intervention was removed, it may be interesting to also have an observer track frequency of and quality of staff interactions with elders across the weeks of the study as it is possible that although the formal gratitude intervention implemented by staff was removed in Week 3, staff may have engaged more with the elders in Week 3 due to increased social connection between staff and elders resulting from the experience of the gratitude intervention. Bearing in mind that implementing the gratitude intervention seems to have improved elder well-being. It may be fruitful to see how a gratitude intervention among nursing staff during regularly scheduled group meetings may improve staff morale.

Further improvement of this study would be to include more objective measures of elder mood and well-being such as tracking smiling frequency or taking measures of elder cortisol levels. Use of more standardized measures would also be an improvement. One study found evidence that suggests that caregivers of patients with dementia may have a tendency to view their patients as more depressed than the patients self-report ${ }^{140}$. Tracking inter-rater reliability among staff raters would also be useful to determine consistency among staff observational ratings of the elders.

In addition, it may be fruitful to compare the results of a gratitude intervention with the outcome of a current events discussion intervention to examine if simply providing a topic to elicit conversation among elders may also improve elder well-being.

Overall, these results are encouraging. They demonstrate that a relatively low cost, group gratitude intervention can benefit elders, including those living with dementia, in a long term care setting. Even with limited staff resources, setting aside time for gratitude in the daily schedule is a relatively feasible and worthwhile intervention.

\section{Acknowledgments}

None.

\section{Conflicts of interest}

Author declares there are no conflicts of interest.

\section{Funding}

None.

\section{References}

1. National Center for Chronic Disease Prevention and Health Promotion, NCDC. Trends in aging: United States and worldwide. MMWR Morb Mortal Wkly Rep. 2003;52(6):101-104.

2. Administration on Aging. A Profile of Older Americans: 2011, USA. 2011. p.1-18.

3. Vincent G, Velkoff V. The next four decades: The older population in the United States: 2010 to 2050. U.S Census Bureau. 2010;1-16.

4. Campbell P. Population projections for states by age, sex, race, and Hispanic origin: 1995-2025. U.S. Bureau of the Census, Population Division. 1996;1-37.

5. He W, Sangupta M, Velkoff V, et al. 65+ in the United States: 2005. Current Population Reports Special Studies. U.S. Census Bureau, Current Population Reports. 2005;23-209.

6. Wolff J, Starfield B, Anderson G. Prevalence, expenditures, and complications of multiple chronic conditions in the elderly. Arch Intern Med. 2002;162(20):2269-2276.

7. Pendlebury ST, Rothwell PM. Prevalence, incidence, and factors associated with pre-stroke dementia: A systematic review and metaanalysis. Lancet Neurol. 2009;8(11):1006-1018.

8. Maraldi C, Lattanio F, Onder G, et al. Variability in the prescription of cardiovascular medications in older patients: Correlates and potential explanations. Drugs Aging. 2009;26(supp11):41-51.

9. Mensah G, Mokdad A, Ford E, et al. State of disparities in cardiovascular health in the United States. Circulation. 2005;111:1233-1241.

10. Raji CA, Ho A, Parikshak N, et al. Brain structure and obesity. Hum Brain Mapp. 2010;31(3):353-364.

11. Yaffe K, Lindquist K, Schwartz A, et al. Advanced glycation end product level, diabetes, and accelerated cognitive aging. Neurology. 2011;77(14):1351-1356

12. Ogden CL, Carroll MD, Kit BK, et al. Prevalence of obesity in the United States, 2009-2010. NCHS Data Brief. 2012;82:1-8.

13. Alzheimer's Association. Alzheimer's disease facts and figures. Alzheimers Dement. 2009;5(3):234-270.

14. Dilworth AP, Palmer M. Annual review of gerontology and geriatrics, Volume 31, 2011: Pathways through the transitions of care for older adults, New York:Springer. 2011.

15. Karel M, Gatz M, Smyer MA. Aging and mental health in the decade ahead: What psychologists need to know. Am Psychol. 2012;67(3):184-198.

16. Lyketsos CG, Lopez O, Jones B, et al. Prevalence of neuropsychiatric symptoms in dementia and mild cognitive impairment: Results from the Cardiovascular Health Study. JAMA. 2002;288(12):1475-1483.

17. Okura T, Plassman BL, Steffens DC, et al. Prevalence of neuropsychiatric symptoms and their association with functional limitations in older adults in the United States: The aging, demographics, and memory study. J Am Geriatr Soc. 2010;58(2):330-337. 
18. McCarthy HJ, Roth D, Goode K, et al. Longitudinal course of behavioral problems during Alzheimer's disease: Linear versus curvilinear patterns of decline. J Gerontol A Biol Sci Med Sci. 2000;55(4):200-206.

19. Erikson E. Vital involvement in old age. New York: Norton. 1986

20. Boiler L, Haverman M, Westerhof G, et al. Positive psychology interventions: A meta-analysis of randomized controlled studies. $B M C$ Public Health. 2013;13:119.

21. Layous K, Chancellor J, Lyubomirsky S, et al. Delivering happiness: Translating positive psychology intervention research for treating major and minor depressive disorders. J Altern Complement Med. 2011;17(8):675-683.

22. Seligman M, Csikszentmihalyi M. Happiness, excellence, and optimal human functioning: Review of a special issue of the American Psychologist. In: Martin EP Seligman \& Mihaly Csikszentmihalyi, guest editors. American Psychologist. 2000;55:5-14.

23. Peterson C, Seligram M. Character strengths and virtues: A handbook and classification. American Psychological Association. 2004. P.800.

24. Froh J, Sefick W, Emmons R. Counting blessings in early adolescents: an experimental study of gratitude and subjective well-being. $J$ Sch Psychol. 2008;46(2):213-233

25. Lambert N, Fincham F, Stillman T. Gratitude and depressive symptoms: The role of positive reframing and positive emotion. Cogn Emot 2012;26(4):615-633.

26. Wood AM, Joseph S, Lloyd J, et al. Gratitude influences sleep through the mechanism of pre-sleep cognitions. J Psychosom Res. 2009;66(1):43-48.

27. Emmons R, McCullough M. Counting blessings versus burdens: An experimental investigation of gratitude and subjective well-being in daily life. J Pers Soc Psychol. 2003;84(2):377-389.

28. Sheldon K, Lyubomirsky S. How to increase and sustain positive emotion: The effects of expressing gratitude and visualizing best possible selves. The Journal of Positive Psychology. 2006;1(2):73-82.

29. Yates T, Masten A. Fostering the future: Resilience theory and the practice of positive psychology. In: Linley P \& Joseph S (Eds.), Positive psychology in practice, John Wiley \& Sons,New Jersey, USA. 2004. p.521-539.

30. Maddux J, Snyder C, Lopez S. Toward a positive clinical psychology: Deconstructing the illness ideology and constructing an ideology of human strengths and potential. In: Linley P \& Joseph S (Eds.), Positive psychology in practice, John Wiley \& Sons, New Jersey, USA. 2004 p.320-324.

31. Bronfenbrenner U. The Ecology of Human Development: Experiments by Nature and Design. HarvardUniversity Press. 1979. p. 352.

32. Sheldon K, King L. Why positive psychology is necessary. Am Psychol. 2001;56(3):216-217.

33. Maddux J. Stopping the "madness": Positive psychology and the deconstruction of the illness ideology and the DSM. In: Lopez S \& Snyder C (Eds.), Oxford Handbook of Positive Psychology. (2nd edn), N.Y. Oxford University Press. 2002. p.61-69.

34. Linley P, Joseph S, Harrington S, et al. Positive psychology: Past, present, and (possible) future. The Journal of Positive Psychology. 2006;1(1):3-16.

35. Compton W. Introduction to Positive Psychology. Belmont, CA Thompson. 2005.

36. Chamie J. World population prospects: The 2002 revision. New York United Nations Department of Economic and Social Affairs, Volume III: Analytical Report. 2004.
37. Charles ST, Reynolds CA, Gatz M. Age-related differences and change in positive and negative affect over 23 years. J Pers Soc Psychol. 2001;80(1):136-151.

38. Carstensen L, Pasupathi M, Mayr U, et al. Emotional experience in everyday life across the adult life span. J Pers Soc Psychol. 2000;79(4):644-655

39. Myers DG, Diener E. Who is happy? Psychological Science. 1995;6(1):10-19.

40. Diener E, Suh EM. Subjective well-being and age: An international analysis. In: Schaie KW \& Lawton MP (Eds.), Annual review of gerontology and geriatrics: Focus on emotion and adult development(Vol. 17, pp. 304-324).New York: Springer. 1998.

41. Wilson AE, Ross M. From chump to champ: People's appraisals of their earlier and present selves. J Pers Soc Psychol. 2001;80(4):572-584

42. Costa P, McCrae R. Trait theories of personality. In: Barone D et al (Eds.), Advanced personality.New York, USA. 1998. p.103-121.

43. Roberts B, Chapman N. Change in dispositional well-being and its relation to role quality: A 30-year longitudinal study. Journal of Research in Personality. 2000;34(1):26-41.

44. Gatz, M, Harris JR, Turk-Charles S. The meaning of health for older women. In: Stanton AL \& Gallant SJ (Eds.), The psychology of women's health: Progress and challenges in research and applicationAmerican Psychological Association, Washington DC, USA. 1995. p.491-530.

45. Blazer DG, \& Koenig HG. Mood disorders. In: Busse EW \& Blazer DG (Eds.), Textbook of geriatric psychiatry, AmericanPsychiatric Press, Washington DC, USA. 1996. p. 235-263.

46. Halpert S, Braunschweig H, Peters ND. The use of the Beck Depression Inventory as a geriatric assessment instrument. Clinical Gerontologist. 1998;20(1):63-74.

47. Williamson GM, Schulz R. Physical illness and symptoms of depression among elderly outpatients. Psychol Aging. 1992;7(3):343-351.

48. Husaini B. Predictors of depression among the elderly: Racial differences over time. Am J Orthopsychiatry. 1997;67(1):48-58.

49. Kurlowicz L. Social factors and depression in late life. Arch Psychiatr Nurs. 1993;7(1):30-36.

50. Aguera OL, Failde I, Cervilla JA, et al. Unexplained pain complaints and depression in older people in primary care. $J$ Nutr Health Aging. 2013;17(6):574-577.

51. Huffstetler B. Depression in older adults: Pervasive or preventable? Adultspan Journal. 2001;3(2):61-70.

52. Lenze E, Rogers J, Martire L, et al. The association of late-life depression and anxiety with physical disability: A review of the literature and prospectus for future research. Am J Geriatr Psychiatry. 2001;9(2):113-135

53. Krishnan K, Delong $M$, Kraemer $H$, et al. Cormorbidity of depression with other medical diseases in the elderly. Biol Psychiatry. 2002;52(6):559-588.

54. Aminadeh F, Byszewski A, Molnar F, et al. Emotional impact of dementia diagnosis: Exploring persons with dementia and caregivers' perspectives. Aging Ment Health. 2007;11(3):281-290.

55. Pearce A, Clare L, Pistrang N. Managing sense of self: Coping in the early stages of Alzheimer's disease. Dementia: The International Journal of Social research and Practice. 2002;1(2):173-192.

56. Cohen D, Kennedy G, Eisdorfer C. Phases of change in the patient with Alzheimer's dementia: a conceptual dimension for defining health care management. J Am Geriatr Soc. 1984;32(1):11-15. 
57. Keady J, Nolan M. IMMEL. 2: Working to augment coping responses in early dementia. Br J Nurs. 1995;4(7):377-380.

58. Pratt R, Wilkinson H. Tell me the truth: The effect of being told the diagnosis of dementia from the perspective of the person with dementia Centre for Social Research on Dementia, University of Stirling. 2001. p. 1-92.

59. Lipinska B, Backman L, Herlitz A. When Greta Garbo is easier to remember than Stefan Edberg: Influences of prior knowledge on recent memory in Alzheimer's disease Psychol Aging . 1992;7(2):214-220.

60. Camp C, Foss J, OHanlon A, et al. Memory interventions for persons with dementia. Applied Cognitive Psychology. 1996;10(3):193-210.

61. Matteson M, Linton A, Barnes S, et al. The relationship between Piaget and cognitive levels in persons with Alzheimer's disease and related disorders. Aging. 1996;8(1):61-69.

62. Thornbury J. Cognitive performance on Piagetian tasks by Alzheimer's disease patients. Res Nurs Health. 1992;15(1):11-18.

63. Farina E, Mantovania F, Fioravanti R, et al. Evaluating two group programmes of cognitive training in mild-to-moderate $\mathrm{AD}$ : Is there any difference between a 'global' stimulation and a 'cognitive-specific' one? Aging \& Mental Health. 2006;10(3):211-218.

64. Judge KS, Menne HL, Whitlatch CJ. Stress process model for individuals with dementia. Gerontologist. 2010;50(3):294-302.

65. Watson LC, Lewis CL, Moore CG, et al. Perceptions of depression among dementia caregivers: Findings from the CATIE-AD trail. Int $J$ Geriatr Psychiatry. 2011;26(4):397-402.

66. Butters MA, Klunk WE, Mathis CA, et al. Imaging Alzheimer pathology in late-life depression with PET and Pittsburgh Compound-B. Alzheimer Dis Assoc Disord. 2008;22(3):261-268.

67. Steinberg M, Shao H, Zandi P, et al. Point and 5-year period prevalence of neuropsychiatric symptoms in dementia: the Cache County Study. Int J Geriatr Psychiatry. 2008;23(2):170-177.

68. Auer S, Sclan S, Yaffe R, et al. The neglected half of Alzheimer's disease: Cognitive and functional concomitants of severe dementia. $J$ Am Geriatr Soc. 1994;42(12):1266-1272.

69. Teri L, Gibbons L, McCurry S, et al. Exercise plus behavioral management in patients with Alzheimer's disease: A randomized controlled trial. JAMA. 2003;290(15):2015-2022.

70. Proctor R, Burns A, Powell $\mathrm{H}$, et al. Behavioural management in nursing and residential homes: A randomized controlled trial. Lancet. 1999;354(9172):26-29.

71. Butler RN. The life review: An unrecognized bonanza. Int J Aging Hum Dev. 1980;12(1):35-38.

72. Baines S, Saxby P, Ehlert K. Reality orientation and reminiscence therapy: A controlled cross-over study of elderly confused people. $\mathrm{Br} J$ Psychiatry. 1987;151:222-231.

73. Cook JB. Reminiscing: How it can help confused nursing home residents. Soc Casework. 1984;65(2):90-93.

74. Kiernat J. The use of life review activity with confused nursing home residents. Am J Occup Ther . 1979;33(5):306-310

75. Hellebrandt FA. Comment: The senile dementia in our midst. The Gerontologist. 1978;18(1):67-70.

76. Liton J, Olstein SC. Therapeutic aspects of reminiscence. Social Casework. 1969;50:263-268.

77. Woods B, Spector A, Jones C, et al. Reminiscence therapy for dementia Cochrane Database Syst Rev. 2005;2:CD001120.

78. Jones E, Beck LR. The use of reminiscence therapy for the treatment of depression in rural dwelling older adults. Issues Ment Health Nurs. 2002;23(3):279-290.
79. Chao $\mathrm{S}, \mathrm{Li} \mathrm{H}, \mathrm{Wu} \mathrm{C}$, et al. The effects of group reminiscence therapy on depression, self esteem, and life satisfaction of elderly nursing home residents. J Nurs Res. 2006;14(1):36-45.

80. Peng X, Huang L, Chen L, et al. Cognitive behavioral therapy and reminiscence techniques for the treatment of depression in the elderly: A systematic review. J Int Med Res. 2009;37(4):975-982.

81. Dietch J, Hewett L, Jones S. Adverse effects of reality orientation. J Am Geriatr Soc. 1989;37(10):974-976.

82. OConnell B, Gardner A, Miyuki H, et al. Clinical usefulness and feasibility of using reality orientation with patients who have dementia in acute care settings. Int J Nurs Pract. 2007;13(3):182-192.

83. Spector A, Orrell M, Davies S, et al. Withdrawn: Reality orientation for dementia. Cochrane Database Syst Rev. 2007;3:CD001119.

84. Woods B, Aguirre E, Spector A, et al. Cognitive stimulation to improve cognitive functioning in people with dementia. Cochrane Database Syst Rev. 2012;2:CD005562.

85. Baker R, Dowling Z, Wareing L, et al. Snoezelen: Its long-term and short-term effects on older people with dementia. British Journal of Occupational Therapy. 1997; 60(5): 213-218.

86. Baker R, Bell S, Baker E, et al. A randomized controlled trial of the effects of multi-sensory stimulation (MSS) for people with dementia. $B r$ J Clin Psychol . 2001;40(pt 1):81-96.

87. Chung J, Lai C, Chung P, et al. Snoezelen for dementia. Cochrane Database Syst Rev. 2002;(4):CD003152.

88. Van Weert JC, Van Dulmen A, Spreeuwenberg Pl, et al. Behavioral and mood effects of snoezelen integrated into 24-hour dementia care. $J \mathrm{Am}$ Geriatr Soc. 2005;53(1):24-33.

89. Camberg L, Woods P, Ooi W, et al. Evaluation of simulated presence: A personalized approach to enhance wellbeing in persons with Alzheimer's disease. J Am Geriatr Soc. 1999;47(4):446-452.

90. Fry W. The physiologic effects of humor, mirth, and laughter. JAMA. 1992;267(13):1857-1858.

91. Lefcourt H, Davidson-Katz K, Kueneman K. Humor and immune system functioning. International Journal of Humor Research 1990;3:305-321.

92. Takahashi K, Iwase M, Yamashita K, et al. The elevation of natural killer cell activity induced by laughter in a crossover designed study. Int $J \mathrm{Mol}$ Med. 2001;8(6):645-650.

93. Stuber M, Hilber S, Mintzer L, et al. Laughter, humor, and pain perception in children: a pilot study. Evid Based Complement Alternat Med. 2009;6(2):271-276.

94. Weisenberg M, Tepper I, Schwarzwald J. Humor as a cognitive technique for increasing pain tolerance. Pain. 1995;63(2):207-212.

95. Takeda M, Hashimoto R, Kudo $\mathrm{T}$, et al. Laughter and humor as complementary and alternative medicines for dementia patients. $B M C$ Complement Altern Med. 2010;10:28.

96. Brodaty H, Low L, Chenoweth L, et al. SMILE: A randomized controlled trial of humour therapy in residential care. Manuscript in preparation. The University of New South Wales. 2011.

97. Orsulic-Jeras S, Judge K, Camp C. Montessori-based activities for longterm care residents with advanced dementia: Effects on engagement and affect. Gerontologist. 2000;40(1):107-111.

98. Biringer F, Anderson J. Self-recognition in Alzheimer's disease: A mirror and video study. J Gerontol. 1992;47(6):P385-388.

99. Camp C, Judge K. An intergeneration program for person with dementia using Montessori methods. Gerontologist. 1997;37(5):688-692.

100. Vance D, Johns R. Montessori improved cognitive domains in adults with Alzheimer's disease. Physical \& Occupational Therapy in Geriatrics. 2002;20(3-4):19-33. 
101. Butler J, Ciarrochi J. Psychological acceptance and quality of life in the elderly. Qual Life Res.2007;16(4):607-615.

102. Langer EJ, Rodin J. The effects of choice and enhanced persona responsibility for the aged: A field experiment in an institutional setting. J Pers Soc Psychol. 1976;34(2):191-198.

103. Rodin J, Langer E. Long-term effects of a control-relevant intervention with the institutional aged. J Pers Soc Psychol. 1977;35(12):897-902.

104. Brown E. Care recipients' psychological well-being: The role of sense of control and caregiver type. Aging Ment Health. 2007;11(4):405-414.

105. Sheldon K, Kasser T . Getting older, getting better? Personal strivings and psychological maturity across the lifespan. Dev Psychol. 2001;37(4):491-501.

106. Erikson E. Childhood and society. ( $2^{\text {nd }}$ edn), New York: Norton, USA. 1963.

107. Sheldon K, Kasser T, Houser-Marko L, et al. Doing one's duty: Chronological age, felt autonomy, and subjective well-being. European Journal of Personality. 2005;19(2):97-115.

108. Deci E, Ryan R. The "what" and "why" of goal pursuits: Human needs and the self-determination of behavior. Psychological Inquiry. 2000;11(4):227-268.

109. Vaillat G. Positive aging. In: Linley P \& Joseph S (Eds.), Positive psychology in practice. New Jersey: Wiley, USA. 2004. p.561-577.

110. McCullough M, Emmons R, Tsang J. The grateful disposition: A conceptual and empirical topography. J Pers Soc Psychol. 2002;82(1):112-127.

111. Watts F, Dutton K, Guilford L. Human spiritual qualities: Integrating psychology and religion. Mental Health, Religion \& Culture. 2006;9(3):277-289.

112. Emmons RA, Crumpler CA. Gratitude as a human strength: Appraising the evidence. Journal of Social and Clinical Psychology. 2000;19(1):56-69.

113. Moore D. Americans most thankful for family and health: Youth also thankful for career/job. Lincoln, NB: The Gallup Poll Monthly. 1996.

114. Smith L. Prayer as an intervention for agitation in dementia residents. Dissertation Abstracts International Section A: Humanities and Social Science. 2008;69:21-59.

115. Chan DW. Gratitude, gratitude intervention and subjective well-being among Chinese school teachers in Hong Kong. Educational Psychology. 2010;30(2):139-153.

116. Seligman M, Steen T, Park N, et al. Positive psychology progress Empirical validation of interventions. Am Psychol. 2005;60(5):410-421.

117. Boehm J, Lyubomirsky S, Sheldon K. A longitudinal experimental study comparing the effectiveness of happiness-enhancing strategies in Anglo Americans and Asian Americans. Cogn Emot. 2011;25(7):1263-1272.

118. Lyubomirsky S, Dickerhoff R, Boehm J, et al. Becoming happier takes both a will and a proper way: An experimental longitudinal intervention to boost well-being. Emotion. 2011;11(2):391-402.

119. Watkins P, Van Gelder M, Frias A. Furthering the science of gratitude. In: Lopez S \& Snyder C (Eds.), Oxford Handbook of Positive Psychology, ( $2^{\text {nd }}$ edn). 2009. p.437-445.

120. Froh JJ, Yurkewicz C, Kashdan TB. Gratitude and subjective wellbeing in early adolescence: Examining gender differences. J Adolesc. 2009;32(3):633-650.

121. McCullough M, Tsang J, Emmons R. Gratitude in intermediate affective terrain: Links of grateful moods to individual differences and daily emotional experience. J Pers Soc Psychol. 2004;86(2):295-309.
122. Watkins PC, Grimm DC, Kolts R. Counting your blessings: Positive memories among grateful persons. Current Psychology. 2004;23(1):52-67.

123. Rind B, Bordia P. Effect of server's "thank you" and personalization on restaurant tipping. Journal of Applied Social Psychology. 1995;25(9):745-751.

124. McCullough M, Kilpatrick S, Emmons R, et al. Is gratitude a moral affect? Psychol Bull. 2001;127(2):249-266.

125. Krause N. Gratitude toward God, stress, and health in late life. Research on Aging. 2006;28(2):163-183.

126. Wood A, Maltby J, Gilett R, et al. The role of gratitude in the development of social support, stress, and depression: Two longitudinal studies.Journal of Research in Personality. 2008;42(4):854-871.

127. Krause N. Religious involvement, gratitude, and change in depressive symptoms over time. Int J Psychol Relig. 2009;19(3):155-172.

128. Fredrickson B, Tugade M, Waugh C, et al. What good are positive emotions in crisis? A prospective study of resilience and emotions following the terrorist attacks on the United States on September $11^{\text {th }}$, 2001. J Pers Soc Psychol. 2003;84(2):365-376.

129. Watkins P, Woodward K, Stone T, et al. Gratitude and happiness: Development of a measure of gratitude, and relationships with subjective well-being. Social Behavior \& Personality: an International Journal. 2003;31(5):431-451.

130. Lyubomirsky S, Sousa L, Dickerhoff R . The costs and benefits of writing, talking, and thinking about life's triumphs and defeats. $J$ Pers Soc Psychol. 2006;90(4):692-708.

131. Lyubomirsky S, Sheldon K, Schkade D. Pursuing happiness: The architecture of sustainable change. Review of General Psychology. 2005;9(2):111-131.

132. Brickman P, Campbell DT. Hedonic relativism and planning the good society. In: Appley MH (Ed.), Adaptation-level theory. AcademicPress, New York, USA. 1971. p. 287-302.

133. Watkins P. Gratitude and subjective well-being. In: Emmons RA \& McCullough ME (Eds.), Psychology of Gratitude. Oxford University Press, New York, USA. 2004. p.167-194.

134. Rabig J, Thomas W, Kane R, et al. Radical re-design of nursing homes: Applying the green house concept in Tupelo, Mississippi. Gerontologist. 2006;46(4):533-539.

135. Calkins M. The physical and social environment of the person with Alzheimer's disease. Aging Ment Health. 2001;5(supply 1):S74-S78.

136. Parmelee P, Lawton M. The design of special environments for the aged. In: Birren J \& Schaie K (Eds.), Handbook of the Psychology of Aging. 1990. p.464-483.

137. Kane RA, Lum TY, Culter LJ, et al. Resident outcomes in small-house nursing homes: A longitudinal evaluation of the initial green house program. J Am Geriatr Soc. 2007;55(6):832-839.

138. Kashdan TB, Mishra A, Breen WE, et al. Gender differences in gratitude: Examining appraisals, narratives, the willingness to express emotions, and changes in psychological needs. J Pers . 2009;77(3):691-730.

139. Sommers S, Kosmitzki C. Emotion and social context: An AmericanGerman comparison. British Journal of Social Psychology. 1988;27(1):35-49.

140. Burke WJ, Roccaforte WH, Wengel SP, et al. Disagreement in the reporting of depressive symptoms between patients with dementia of the Alzheimer type and their collateral sources. Am J Geriatr Psychiatry. 1998;6(4):308-319. 